\title{
El diálogo en la implementación de normas de RSE como promotor del ejercicio adecuado de derechos: un enfoque a partir de la ética del discurso de Jürgen Habermas
}

\author{
GUSTAVO ZAMBRANO CHÁVEZ*
}

\begin{abstract}
SUMARIO: I. INTRODUCCIÓN.- II. ANÁLISIS DE LA RSE DESDE UN ENFOQUE ÉTICO-NORMATIVO.- III. PRINCIPALES CRÍTICAS AL ENFOQUE DE LAS RELACIONES ENTRE CORPORACIONES Y GRUPOS DE INTERÉS.IV. DESARROLLO DE LAS RELACIONES CON LOS GRUPOS DE INTERÉS.V. PERFECCIONAMIENTO EN LA PRÁCTICA DE LA RSE COMO RESULTADO DEL DIÁLOGO CON LOS STAKEHOLDERS: UN ENFOQUE A PARTIR DE LA ÉTICA DEL DISCURSO DE HABERMAS.- VI. PARA CONCLUIR: COMUNIDAD DE PARES IGUALES IMPLICA EJERCICIO DE DERECHOS.
\end{abstract}

\section{INTRODUCCIÓN}

La Responsabilidad Social Empresarial (RSE) tiene diversas maneras de entenderse. Hay quienes consideran que es una forma de actuar que asumen las empresas al momento de hacer su trabajo (corporate behavior/ performance/citizenship). En tanto actuación, se sostiene en la consideración de los efectos de aquellas acciones y decisiones que llevan a cabo las empresas para alcanzar sus fines, así como de los posibles daños que se puedan ocasionar al realizarlas. También la RSE personifica un tipo de filosofía corporativa que toma en cuenta las expectativas sociales, es decir, lo que se espera que una empresa debe hacer.

Estos enfoques se han visto complementados cuando se aceptó que las empresas asumen una relación horizontal —una suerte de red de relaciones sociales (social network) ${ }^{1}$ — con todos aquellos grupos que poseen algún tipo de interés en la manera cómo, al realizar el negocio, este los afecta (stakeholders). Se afirma así que las acciones del negocio impactan en actores sociales o en grupos de interés durante su cotidiano desenvolvimiento — por ejemplo, pueden cambiar sus expectativas de vida-, por lo que es necesario saber cómo se genera esta afectación.

* Es abogado egresado de la Pontifica Universidad Católica del Perú, con estudios de maestría en Ética Aplicada en los Negocios por Linköping Universtittet, Suecia, y NTNU, Noruega, del programa Erasmus Mundus (UE). Se ha desempeñado como docente universitario en cursos de Sociología del Derecho en la PUCP, y de Metodología para la Investigación, Ética, Ética Aplicada a los Negocios, y Análisis del Conflicto Socio Ambiental en la UPC. Ha trabajado como investigador y ha realizado consultorías en temas relacionados con formalización de la minería artesanal, manejo del conflicto socio-ambiental desde una perspectiva de responsabilidad social-empresarial, de ciudadanía y de participación, y de derechos de los pueblos indígenas y consulta previa en el Perú.

1 Este modelo fue propuesto en 1997 por T. J. Rowley en un artículo titulado «Moving beyond dyadic ties: a network theory of stakeholders influences». Academy of Management Review, № 22 (4), 1997, p. 890 . 
Son muchos los autores que señalan que en el trabajo empresarial se debe considerar este nivel de influencia y de interacción al tomar decisiones. Ello apunta a no generar cambios negativos o conflictos de interés con tales grupos. Al contrario, lo que se debe buscar es reforzar los niveles de confianza e interacción con ellos. Así, la RSE presume necesariamente $-\mathrm{y}$ de manera complementaria — no solo cumplir las obligaciones del negocio, sino además reconocer los grupos de interés y la manera cómo sus expectativas influyen en el trabajo empresarial. Hacerlo permite pensar en la influencia social en y desde el proceso del negocio, dentro de parámetros que busquen la mejora de la calidad de vida de las personas (responsabilidad ética) y la obtención de utilidades (rentabilidad).

Si esta aproximación sobre RSE se dirige hacia el trabajo de las empresas extractivas, tal deberá entenderse de la siguiente manera: tomar en cuenta el cumplimiento de las exigencias del negocio —y así conseguir los fines de la organización (por ejemplo, la explotación y extracción de un mineral) - y, al mismo tiempo, seguir y respetar una serie de parámetros, ya sea establecidos por la normatividad o el mercado - por ejemplo, la ley-, y principios y líneas de acción que se encuentran dentro del plano de lo que la sociedad espera como una conducta responsable que no los afecte negativamente — por ejemplo, desplazamientos involuntarios-.

Podemos ser aun más específicos con respecto a lo previamente señalado. Pensar el trabajo en una empresa extractiva como la minería es la conjugación de cuatro ámbitos que definen cómo decidir el inicio de las operaciones, siempre vistos como constantes e interdependientes: el ámbito financiero/económico (buscar obtener rentabilidad), el tecnológico (emplear recursos técnicos para extraer un recurso), el ambiental (sostenibilidad y cuidado del entorno) y el social. En el caso de este último, se busca seguir aquellas premisas que ayuden a consolidar una convivencia en condiciones de equidad, respeto y diálogo continuo entre la empresa extractiva y las comunidades locales —usualmente asentadas cerca del área de influencia del proyecto-. Este diálogo (intercultural) se ve plasmado, por ejemplo, con la obtención de la licencia social en el caso minero - una suerte de contrato social o de pacto de convivencia-. Tal se obtiene cuando, entre los grupos locales, existe confianza acerca de que - entre otras cosas - la empresa minera no va a afectar sus condiciones de vida de manera agresiva. Esta expectativa de cambios que no sean generadores de rechazo incluye proteger el medio ambiente, no contaminar recursos — como el agua o el suelo-, promover políticas para el desarrollo local, respetar a las personas, los grupos locales y la sociedad en general, no afectar la vida de los trabajadores al exponerlos a actividades riesgosas, entre otras.

Sin esta licencia o garantía de que existe confianza y diálogo permanente, las actividades extractivas mineras no se ven respaldadas por la sociedad. 
Así, la falta de la licencia social puede ser un indicador de que exista una situación de conflicto con comunidades locales que no se ha logrado manejar de manera adecuada. Entonces será vital un acercamiento realmente sincero en condiciones de respeto y equidad con estos grupos para que la actividad se desenvuelva dentro de lo deseable —es decir, sobre el plano de lo ético-.

Pero cada contexto de conflicto es distinto, y al mismo tiempo comparten premisas para analizarlos. Podemos señalar como constante en estos que muchos grupos o comunidades locales partícipes en su dinámica, en algún momento de la toma de decisiones corporativas, no fueron vistos como parte del giro del negocio extractivo, a pesar de esfuerzos realizados para ello. Sobre esta línea, hay quienes afirman que sus intereses y sus expectativas no son considerados de manera oportuna ni adecuada al establecer prioridades empresariales. Así, al llevar a cabo la extracción, las visiones diferentes sobre lo que es desarrollo, o la poca identificación de intereses reales, han permitido la consolidación de posicionamientos antagónicos y la generación del conflicto.

Entonces es responsabilidad de la empresa extractiva contar con un enfoque de RSE que pueda representar la adecuación del giro del negocio con una actitud responsable hacia el entorno social. Por ello, si la intención es la extracción de minerales, esta no puede llevarse a cabo sin considerar de qué manera esta actividad va a afectar $-\mathrm{O}$ está afectando- - a estos grupos, los cuales, en un país como el Perú, suelen ser los más vulnerables y alejados de las políticas estatales. Por ello, es imperativo señalar que las empresas pueden ser rentables y responsables al mismo tiempo, si saben tomar decisiones a partir de los enfoques correspondientes ${ }^{2}$.

Luego de lo desarrollado, consideramos que resulta necesario profundizar aun más acerca de cómo hacer efectivas las premisas de la RSE en acciones y prácticas concretas en el Perú. Si bien no es intención del presente artículo desarrollar una metodología que así lo haga, nuestra intención sí es demostrar que la RSE no solo apunta a mejorar las condiciones de convivencia entre centros extractivos trasnacionales y comunidades locales nacionales, sino que ello se puede hacer a partir del diálogo, que a su vez garantiza el ejercicio adecuado de derechos. Al ser demostrada, esta hipótesis, si se considera oportuna, deberá luego considerarse como eje transversal de cualquier metodología que tenga como objetivo real el respeto de las expectativas sociales de las comunidades locales en la toma de decisiones empresariales.

Así, planteamos el artículo a manera de un ensayo que parte de la ética práctica y la teoría del Derecho en cinco secciones. En la primera, se

EL DIÁLOGO EN LA IMPLEMENTACIÓN

DE NORMAS DE

RSE COMO PRO-

MOTOR DEL EJER-

CICIO ADECUADO

DE DERECHOS: UN

ENFOQUE A PARTIR

DE LA ÉTICA DEL

DISCURSO DE JÜR-

GEN HABERMAS 
presentan las premisas más importantes acerca de lo que es la RSE a partir del enfoque de la teoría de los grupos de interés y el caso se delimita a las comunidades locales. Esto facilitará entender las razones que justifican por qué las empresas —en especial las extractivas - poseen responsabilidades sociales. Una segunda parte expondrá las críticas más resaltantes contra el enfoque de la RSE y cómo tales argumentaciones adolecen de inconvenientes en su fundamentación. La tercera y cuarta parte propondrán comprender la RSE a partir de la importancia del diálogo entendido desde la teoría de la ética discursiva de Jürgen Habermas. Finalmente, se planteará la propuesta que trata de demostrar cómo este enfoque habermasiano de diálogo en la RSE consolida el debido ejercicio de derechos.

\section{ANÁLISIS DE LA RSE DESDE UN ENFOQUE ÉTICO-NORMATIVO}

Por motivos metodológicos, tomemos la siguiente afirmación como cierta: la sociedad, en general, posee dos expectativas hacia la manera cómo las empresas hacen su trabajo. La primera es que las empresas deben trabajar de manera adecuada para alcanzar sus fines. Ello supone que la producción de bienes y servicios y la obtención de ganancia económica se lleven a cabo dentro de parámetros que no afecten negativamente la vida de las personas. La segunda expectativa — relacionada con la anterior - considera que la sociedad espera una conducta empresarial responsable durante la interacción entre empresas e individuos y colectividades.

Tales expectativas resultan una base fundamental sobre la cual se discuten y elaboran marcos referenciales en los que se presenta la RSE como concepto. En este sentido, dicha base supondrá que, al hablar de RSE, consideraremos cómo las empresas deberían relacionarse con la sociedad y los individuos. Así, se podría entender como una obligación social de carácter moral al hacer negocios.

Sin embargo, conceptualizar la RSE no es un debate acabado: se sigue discutiendo sobre cómo actuar responsablemente ${ }^{3}$. Pero, a pesar de la falta de consenso, sí se puede afirmar lo siguiente: las empresas tienen que ser responsables en su manera de hacer negocios. Es decir, tienen que tener políticas de RSE que sean transversales e integrales a sus procesos corporativos. Revisemos las razones detrás de esta afirmación a partir de uno de los modelos más aceptados y citados de RSE, propuesto por Archie Carroll en $1979^{4}$.

3 Actualmente, la Organización Internacional para la Normalización (ISO) viene culminando el proceso de elaboración de una norma internacional que provea una guía para la responsabilidad social (ISO 26000). Cuando esta norma se publique —durante el primer semestre de 2010—, se contará con información sobre lo que se entiende por responsabilidad social, que pueda ser útil tanto a las empresas como a los académicos, a la sociedad civil y a los gobiernos.

4 CARroll, A., «A three-dimensional conceptual model of corporate performance». Academy of Management Review, № 4, 1979, pp. 497-505. 
El trabajo de A. Carroll establece que, al hablar de RSE, hay que hacerlo a partir de cuatro tipos de responsabilidades ${ }^{5}$. Tales, en conjunto, completan una manera de actuar desde, por y para las empresas en su relación con la colectividad, tanto hacia dentro como hacia afuera. Por ello, representan, además, el tipo de acciones que deben determinar la manera cómo administrar el negocio, diseñar los procesos productivos, definir su relación con trabajadores y clientes, etcétera.

Las responsabilidades se pueden entender como un todo - Carroll las representa a manera de pirámide - que sirve para identificar el tipo de expectativas sociales a considerar en la toma de decisiones corporativas. Con ello, las empresas, al observarlas como normas a seguir y respetar, alcanzarían una conducta responsable. Carroll señala, así, que una empresa debe cumplir con responsabilidades económicas, legales, éticas y filantrópicas con el objeto no solo de alcanzar sus fines (ganancia, rentabilidad, producción de bienes y servicios, etcétera), sino, además, de cumplir con las expectativas sociales. Revisemos cada una de estas:

- Responsabilidades económicas (requeridas por la sociedad). Son la base de la pirámide, en tanto se entiende que las empresas son instituciones económicas. La generación de ganancia es parte de la manera cómo las empresas deben dirigir su manera de trabajar (producir bienes/brindar servicios). En ese sentido, se espera que, a partir de un trabajo adecuado, las empresas obtengan suficiente ganancia como para cumplir con aquellas obligaciones en las que la satisfacción de la expectativa monetaria exista: por ejemplo, el pago de salarios adecuados a sus trabajadores, el cumplimiento oportuno en la repartición de ganancias a accionistas, etcétera.

- Responsabilidades legales (requeridas por la sociedad). Las empresas están en la obligación de respetar la ley y las regulaciones estatales. Las normas de un sistema de leyes reflejan, en un sentido, normas éticas y sociales codificadas. En su contenido encierran nociones fundamentales acerca de las que se pueden considerar prácticas justas establecidas por el legislador.

- Responsabilidades éticas (esperadas por la sociedad). De acuerdo con Carroll, representan aquellas actividades y prácticas que son esperadas o rechazadas por los miembros de una sociedad, a pesar de que tales no se encuentran codificadas en la ley ${ }^{6}$. En otras palabras, las responsabilidades éticas implican aquellas normas y expectativas que exigen los clientes, empleados, accionistas, y la sociedad: lo justo, lo correcto o lo razonable.

5 Al respecto, se pueden revisar las siguientes obras de Archie Carroll: CARROLL, A. y A.K. BUCHHOLTZ. Business \& society. Ethics and Stakeholder Management. Sexta edición. Mason Ohio: SouthWestern Lenguage Learning, 2006. CARROLL, A. «The four faces of corporate citizenship». En Business and Society Review, № 100/101, 1998, pp. 1-7; CARROLL, A. «The pyramid of corporate social responsibility: towards the moral management of organizational stakeholders". Business Horizons, julio - agosto de 1991.

6 CARROLL, A. y A.K. BuChHOLTZ. Business \& society. Óp. cit., p. 37. 
- Responsabilidades filantrópicas (deseadas por la sociedad). Reflejan las expectativas de la población hacia los negocios. Se diferencian de las anteriores en tanto estas actividades son voluntarias, no requieren el mandato de la ley y no representan expectativas de negocio en un sentido ético. Nacen de la voluntad de la empresa por querer hacer algo sin que exista una obligación.

La propuesta de Carroll señala cuáles son las responsabilidades que una empresa posee. La claridad en su clasificación ha hecho que tal planteamiento haya influenciado en otras maneras de conceptualizar la RSE. ${ }^{?}$ Por ello, lo destacamos y lo consideramos el eje sobre el cual comprender nuestro trabajo: las empresas cuentan con una serie de responsabilidades, y estas están entendidas a partir de lo que una empresa está en la obligación de hacer y lo que la sociedad espera que haga. Adicionalmente a lo afirmado, esas responsabilidades pueden ser identificadas, categorizadas y pauteadas por las empresas para saber qué hacer o cómo tomar decisiones. Luego, en palabras de Carroll, la RSE se definirá como «[...] el conjunto de expectativas económicas, legales, éticas y filantrópicas que la sociedad tiene de las organizaciones en un momento determinado de tiempo» ${ }^{8}$, donde su cumplimiento debe entenderse no como secuencial sino como integral?.

Sin embargo, para mejorar esta posición es necesario considerar, además, a aquellos a quienes las organizaciones empresariales les son responsables. Si hablamos de responsabilidades sociales, esta última palabra representa en sí misma un escenario al cual denominamos sociedad.

7 La perspectiva de A. Carroll ha sido revisada por diversos autores. Muchas propuestas se han presentado a partir de tales revisiones. Y muchas de ellas han evidenciado cómo el concepto de Carroll ha influenciado la manera de entender lo que es una responsabilidad social corporativa. En ese sentido, mencionaremos algunas de estas definiciones que se han presentado en el debate académico en la promoción de la RSE, y que consideran la perspectiva de Carroll. D. Wood señala que: «En la base de la concepción de la RSE, se encuentra la relación que existe entre la ética y los negocios» (en WOOD, D. "Corporate social performance revisited». Academy of Management Review, vol. 4, 1991, p. 698). Baron sostiene que la RSE implica la "Satisfacción de necesidades más allá de las que obliga el mercado y la ley. Excluye las acciones sociales que tienen como único objetivo lograr utilidades o que responden a grupos de presión que ponen en riesgo la competitividad de la empresa" (en BARON, D. Private politics, corporate social responsibility, and integrated strategy. Research Papers. Stanford University Graduate School of Business, 2001, p. 768). McWilliams y Siegell consideran que la RSE son «Acciones que pretenden promover algunos bienes sociales, y que van más allá de los intereses de la empresa y de los requerimientos legales" (en MCWILLIAMS, A., y D. SIEGEL. "Corporate social responsibility and financial performance: correlation or misspecification?». Strategic Management Journal, № 21 (5), 2000, p. 607). Con relación a organizaciones que promueven la RSE, The Global Compact al hablar de RSE lo hace desde la ciudadanía corporativa, la cual «[...] permite la conciliación de los intereses y procesos de la actividad empresarial con los valores y demandas de la sociedad civil» (en <www.unglobalcompact.org>). El World Business Council for Sustainable Development, por otro lado, sostiene que la RSE es un "Compromiso permanente de los negocios para conducirse éticamente y para contribuir al desarrollo económico mientras mejoran la calidad de vida de sus empleados y de sus familias, así como de su comunidad y de la sociedad en general» (en <www.wbcsd.org>). Finalmente, el Business for Social Responsibility nos dice que, cuando hablamos de RSE, lo hacemos desde actividades que buscan "conducir una empresa de modo que cumpla o exceda las expectativas éticas, legales, comerciales y públicas que la sociedad tiene respecto de los negocios» (en <www.bsr.org>).

8 "The [corporate] social responsibility of business encompasses the economic, legal, ethical, and discretionary (philanthropic) expectations that society has of organizations at a given point in time" CARROLL. The four faces of corporate citizenship. Óp. cit., p. 1-7.

9 Ibíd., p. 5. 
En este, las empresas juegan un rol activo - llevan a cabo acciones-, y al hacerlo pueden generar impactos en quienes interactúan con ellas. Lo mencionado amplía la visión de la RSE al personalizar a los grupos a los que las empresas les deben respuestas de sus acciones. Para reconocer los diferentes grupos con los que las empresas se pueden relacionar cuando hacen negocios, consideramos importante tomar en cuenta la ya clásica Teoría de los Grupos de Interés —o Teoría de los Stakeholders— de Edward Freeman ${ }^{10}$, considerada una fuente sólida de ideas acerca de cómo administrar la empresa ${ }^{11}$.

La propuesta de Freeman se centra en integrar e identificar grupos sociales con un interés en o con las actividades de la empresa. Define a estos grupos de interés o stakeholders como «cualquier grupo o individuo beneficiado o afectado, y cuyos derechos son violados o respetados por las actividades empresariales $»^{12}$. Más específicamente, su aproximación incluye como stakeholders a proveedores, clientes, empleados, accionistas y a las comunidades locales, entre otros, quienes de alguna manera verán su vida influenciada por lo que la empresa haga o decida hacer ${ }^{13}$.

La idea central de esta teoría es que las empresas entablan una relación fiduciaria con todos aquellos grupos e individuos que admiten un interés o un reclamo hacia ellos. Entonces, la empresa se deja de ver como una entidad aislada del contexto y del resto de actores sociales: asume un rol actuante y definido a partir de entender cómo se relaciona con otros actores.

$\mathrm{Al}$ ser el fin u objeto de una corporación la dación de bienes y servicios a la sociedad para la obtención de una ganancia que sea rentable, entender cuál es el rol que cumplen y las influencias en los grupos e individuos permite, a su vez, comprender mejor si es que sus fines se cumplen o no. Por ello, se puede afirmar que las empresas deben considerar, en la toma de decisiones de negocios, los intereses de estos grupos, incluso si estos intereses no significan una generación de ganancia ${ }^{14}$. En ese sentido, de acuerdo con Freeman ${ }^{15}$ :

10 Freeman, R.E. «A stakeholder theory of the modern corporation». En L. Princus (editor). Perspectives in business ethics. Chicago: McGraw Hill, 1984, pp. 171-181.

11 Esta aproximación no es nueva. Ya antes había sido presentada y trabajada por el mismo A. Carroll en el ya citado artículo de 1991, «The pyramid of corporate social responsibility...».

12 FREEMAN, R.E. Strategic management: a stakeholder approach. Boston: Pitman, 1984.

13 La Teoría de los Grupos de Interés ha ido mejorando con el tiempo a partir de haber sido trabajada desde un enfoque más práctico a partir de las siguientes preguntas: (1) ¿cómo identificar a los stakeholders? y (2) ¿quiénes están o no interesados en las actividades de la empresa? Cabe mencionar, por ejemplo, el trabajo de M. Clarkson, quien propone que existen grupos de intereses primarios y secundarios. En ese sentido, define a los grupos de interés primarios como aquellos grupos que son esenciales para las operaciones de una empresa. Los secundarios, por otro lado, son aquellos grupos que, aunque influyen o se ven influenciados por las actividades de las empresas, no son ni participan en intercambios económicos con la empresa ni son fundamentales para su supervivencia práctica. CLARCKSON, M.B.E. "A stakeholder framework for analyzing and evaluating corporate social performance». Academy of Management Review, vol. 20, 1995, pp. 92-117.

14 FREEMAN. L. cit.

15 Ibíd., p. 47. 
- Las empresas deben considerar, en su trabajo, a los diferentes grupos con los que interactúa en su contexto social y ambiental, así como sus expectativas.

- Las empresas deben cambiar su estilo de hacer negocios en sus procesos de toma de decisiones hacia un estilo que considere el ambiente externo a la compañía y las expectativas sociales.

Si la RSE representa la manera de actuar de las empresas cuando trabajan o interactúan con la sociedad, considerando las expectativas sociales de los grupos de interés, entonces tener buenas relaciones con dichos grupos de interés o stakeholders representa cómo las empresas han aplicado la RSE. Esta afirmación supone una expectativa social y una obligación moral para las corporaciones. En este sentido, la RSE basada en la teoría de los grupos de interés se considera una teoría ética normativa —nos dice qué hacer y cómo hacerlo— ${ }^{16}$ que, al mismo tiempo, representa una teoría sobre cómo las empresas deben actuar —es decir, una filosofía para hacer negocios_- ${ }^{17}$. Pero adicionalmente la RSE deberá entenderse como una manera para gestionar los negocios: no solo abordar el debate desde lo fundamentalmente abstracto, sino necesariamente también desde la práctica. Es decir, considerar la importancia del rol de cada stakeholder presume tomar en cuenta sus intereses cuando se toman las decisiones corporativas que se ejecutan en acciones concretas del negocio. Así, se puede sumar a lo ya dicho hasta ahora que las responsabilidades sociales de las empresas son las obligaciones que

16 Para definir ética normativa, tomaremos en cuenta la propuesta de S. Kagan, quien considera que tal enfoque ético involucra propuestas sustanciales - directivas de la conducta en algunos casosacerca de cómo actuar, cómo vivir o qué clase de persona ser. En S. KAGAN, Normative ethics. Boulder: Westview Press, 1998, p. 4.

17 La Teoría de los Grupos de Interés de E. Freeman ha sido complementada por muchos estudiosos de la ética normativa. Por ejemplo, J. E. Post et al. en su artículo «Managing the extended enterprise: the new stakeholder view", plantea una interesante perspectiva de esta teoría al indicar cómo las empresas pueden contribuir al bienestar social. Estos autores argumentan que «[...] la Teoría de los Grupos de Interés considera que las empresas tienen obligaciones tanto a los accionistas de la empresa como a los individuos y grupos que contribuyen, ya sea de manera voluntaria o no, en la capacidad de o en las actividades de generación de ganancia de una empresa, y que por ello son potenciales beneficiarios y/o afectados" (POST, J.E., L.E., PRESTON y S. SACHS. «Managing the extended enterprise: the new stakeholder view». California Management Review, vol. 45, №1, 2002, p. 17). J. Smith considera que, según la Teoría de los Grupos de Interés, «[...] los ejecutivos de una empresa son funcionarios de todos los interesados y tienen dos responsabilidades: garantizar que los derechos éticos de las partes interesadas se respeten y equilibrar los intereses legítimos de ellos en la toma de decisiones [empresariales]" (SMITH, J. «The shareholders vs. stakeholders debate». MIT Sloan Management Review, 2003, p. 86). D. Donalson y L.E. Parson sostienen que la teoría tiene un núcleo normativo que guía las operaciones de las corporaciones, basada principalmente en dos razones: (1) los interesados son personas o grupos con intereses legítimos en el procedimiento y/o los aspectos sustantivos de la actividad empresarial; y (2) los intereses de todos los stakeholders son un valor intrínseco (DONALDSON T. y T. DUNFEE. Ties that bind: a social contract approach to business ethics. Boston: Harvard Business School Press, 1999). Así, este grupo de autores presentan no solo la idea de que la sociedad espera que las empresas guíen su actuación sobre la base de las responsabilidades que tienen, sino también por su papel como promotores del bienestar social y del respeto a las personas. 
tienen con sus grupos de interés ${ }^{18}$ y que asumen en la manera cómo se gestiona el negocio ${ }^{19}$.

Luego de presentar esta base conceptual, cabe recordar que tal se ha hecho para enfocarnos hacia uno de los objetivos de este trabajo: preguntarnos si las buenas relaciones entre las empresas extractivas y los grupos locales cercanos a sus centros de extracción guiados por la RSE permiten un real ejercicio de derechos. Dentro de esta lógica, si consideramos que las empresas se relacionan con diferentes tipos de grupos de interés, entonces deben cumplir con diferentes tipos de obligaciones. Se puede afirmar, por ejemplo, que las empresas deben ser rentables para cumplir con los intereses de los accionistas, que deben obedecer la ley que exigen las entidades estatales, que deben sacar al mercado buenos productos o brindar servicios de calidad a sus clientes, que deben seguir pautas de respeto al trabajador en tanto persona a partir de un enfoque de derechos humanos, etcétera. Y si reconocemos que los intereses de los grupos de interés pueden ser identificados por las corporaciones a partir de la Teoría de Stakeholders, podemos afirmar que una empresa puede tener conocimiento sobre cómo guiar sus acciones

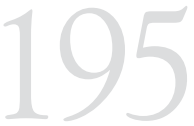

EL DIÁLOGO EN LA IMPLEMENTACIÓN

DE NORMAS DE

RSE COMO PRO-

MOTOR DEL EJER-

CICIO ADECUADO

DE DERECHOS: UN

ENFOQUE A PARTIR

DE LA ÉTICA DEL

DISCURSO DE JÜR-

GEN HABERMAS

18 ¿Por qué las empresas cuentan con responsabilidades cuando interactúan con grupos de interés? Responderé esta pregunta con dos aproximaciones teóricas de la ética empresarial: el enfoque del contrato social y la teoría kantiana del trabajo corporativo. Ambas son importantes porque representan los planteamientos éticos normativos que han influenciado y ayudado a desarrollar luego la Teoría de los Grupos de Interés de Freeman. El enfoque del contrato social considera a las empresas como instituciones sociales —un gobierno, por ejemplo— en constante interacción con los grupos de interés. Esta interacción se basa en acuerdos/pactos libres o contratos, regidos por las normas sociales, que establecen alcanzar un fin positivo para ambas partes. D. Donaldson y W. Dunfee, ambos exponentes de esta teoría, sostienen que las normas sociales sirven como base de las normas de comportamiento de las empresas en su interacción con las partes interesadas. Así, para las empresas, un comportamiento socialmente responsable sería un apoyo en el desempeño corporativo, congruente con las normas sociales imperantes, los valores y expectativas. El acuerdo social significa entonces que la sociedad permite a los negocios que existan solo con la condición de que se traten de beneficiar a todos sus interlocutores. Es decir, las empresas tienen que cumplir con las obligaciones sociales para contribuir al bien de las partes interesadas (bienestar), como si ello fuera parte de un pacto intrínseco. Así, la RSE no está motivada por el interés comercial, sino porque es parte de cómo los interesados esperan que las empresas operen con base, principalmente, en las normas sociales y contractuales de los acuerdos. Véase DonALDSON T. y T. DunfEE. Ties that bind... Óp. cit. Por otro lado, la versión kantiana de la Teoría de los Grupos de Interés se sostiene sobre la base de la idea de la motivación moral desinteresada (enlightened self-interest). Evan y Freeman consideran, como fundamento de esta teoría, la noción kantiana de respeto a las personas: cada persona tiene derecho a no ser tratado como un medio sino un fin en sí mismo. En ese sentido, argumentan que «el propósito de la empresa es servir como vehículo para la coordinación de los intereses de las partes interesadas. [...] La empresa sirve [así] para el beneficio de los grupos de interés, y ninguno puede ser utilizado como un medio para los fines de, otro sin el pleno derecho de participación en esa decisión». EVAN, W. y E. FREEMAN. "A stakeholder theory of the modern corporation: Kantian capitalism». En T. Beauchamp y N. Bowie (editores). Ethical theory and business. Nueva York: Prentice Hall, 1998, pp. 75-93. Por ello, los grupos de interés deben participar en la determinación de la dirección futura de la empresa.

19 Son varias las iniciativas que han venido asumiendo la RSE desde el enfoque de stakeholders y la consideración de tal como una manera de gestionar los negocios. Algunas de las más importantes iniciativas organizadas de promoción de la RSE que consideran esta aproximación son las siguientes: Perú 2021 entiende por RSE una «Forma de gestión que implica inclusión de las expectativas de todos los grupos relacionados a la empresa para lograr el desarrollo sostenible» (en <www.peru2021. org>); el Instituto ETHOS de Empresas y Responsabilidad Social considera que es «Una forma de gestión que supone la relación ética de la empresa con todos sus stakeholders, y el establecimiento de metas empresariales compatibles con el desarrollo sustentable de la sociedad, preservando recursos medioambientales y culturales para las generaciones futuras, respetando la diversidad y promoviendo la reducción de las desigualdades sociales» (en <www.ethos.org.br>); el Instituto Argentino de Responsabilidad Social Empresarial señala que la RSE es un «Modelo de gestión de la compañías que contempla los impactos económicos, sociales y medioambientales derivados de la actividad empresarial. Implica el compromiso renovado de las empresas con la comunidad, con su entorno y con sus públicos de interés" (en <www.iarse.org>). 
luego de incluir expectativas sociales. Pero identificar los intereses de unos stakeholders será más fácil que los de otros.

En el caso de las comunidades locales, las compañías necesitan poner en práctica una mirada más amplia, que cruce más allá de lo que se aprecia fuera de las paredes donde se trabaja. Deben - y pueden - mirar a la ciudad, a la sociedad o al país donde se encuentran o están localizadas. A diferencia de accionistas o trabajadores, es compleja tanto la identificación de estos grupos locales como la manera de definirlos.

Sobre esta línea de pensamiento, McAlister y otros definen a la comunidad local como «todos aquellos miembros de la sociedad consientes de su relación [con las empresas], o considerados, o en cierto sentido afectados, por las operaciones y la producción de la organización empresarial ${ }^{20}$. Tal afirmación representa un punto de inicio acerca de cómo saber qué constituye el grupo de interés llamado comunidad local. Sin embargo, aún es muy general. Para cumplir nuestro objetivo, en el presente trabajo la comunidad local será considerada a partir de lo que McAlister y otros señalan, pero focalizando nuestro debate en aquel grupo de personas que viven alrededor de las instalaciones de una compañía o empresa y con quienes interactúa constantemente porque son parte de su área de influencia. Es decir, si reconocemos que los grupos de interés pueden ser ubicados en la sociedad de acuerdo a su relación con las actividades de la empresa, o que tienen un interés para con esta, o que sus derechos se pueden ver afectados por lo que haga o deje de hacer, tales grupo locales inicialmente serán quienes habitan cerca o en un área de influencia cercana a las instalaciones corporativas, y estarían identificados, además, por los niveles de impacto que sienten que la empresa les genera.

Siguiendo a Freeman, en su relación con los grupos locales (comunidades), las empresas no pueden exponerlos a daños inaceptables como resultado de su manera de trabajar, incluidas la contaminación ambiental y la exposición a residuos tóxicos ${ }^{21}$. El autor agrega que, si las empresas identifican algún tipo de posible peligro que impacte en los grupos locales, deberá informarles y trabajar con ellos para evitar cualquier problema. Como resultado de esta conducta, la relación entre las empresas y los grupos locales estaría basada en la no generación del daño, mientras se trabaja con el objetivo de alcanzar los beneficios del negocio. Por ello, se afirma que los grupos locales esperan como un comportamiento responsable que las empresas no los afecten negativamente en su manera de vivir.

En el caso de las empresas extractivas, se menciona que las preocupaciones de las comunidades cercanas a centros empresariales de extrac-

20 MCAlister, T., O.C. FerRel y L. FerRel (editores). Business and society. A strategic approach to social responsibility. Boston: Houghton Mifflin Company, 2005, p. 211.

21 FREEMAN. Óp. cit., p. 50. 
ción de recursos incluyen la posible contaminación del medio ambiente, cambios en el uso de la tierra o de las vías de acceso a centros poblados, ventajas económicas positivas que puedan generarse en la región, discriminación contra la comunidad, abuso de personal contratado, proyectos de desarrollo que pueden ser ejecutados en beneficio de la colectividad, trabajos conjuntos que busquen acercamientos con los vecinos, monitoreos participativos, entre otras. Tales preocupaciones suponen que, al llevar a cabo su trabajo, las empresas puedan afectar tanto positiva como negativamente a estos grupos. Por ello, las empresas extractivas deben reconocer no solo a estos grupos locales que rodean sus centros de extracción, sino que además deben identificar cómo sus actividades podrían afectar la vida de dichos grupos humanos. En ese sentido, la RSE deberá considerarse como un conjunto de lineamientos que perfilan obligaciones que las empresas deben tener en cuenta al relacionarse con comunidades locales, esto para no generarles posibles daños ni cambios en su manera de vivir2 ${ }^{22}$.

Así, si una empresa tiene como objetivo extraer un recurso mineral que se encuentra debajo de una montaña, es probable que aquellos pueblos cercanos a la montaña puedan verse afectados por este interés empresarial. Si ello ocurre, las empresas encargadas de llevar a cabo la explotación deben considerar cómo relacionarse con estas comunidades en orden de no generarles impactos negativos. En otras palabras, ante el trabajo empresarial minero, se debe presentar la siguiente pregunta, cuya respuesta además deberá en lo posible apuntar, entre otros objetivos, a la generación de confianza —o de licencia social—: ¿cómo alcanzar mi objetivo de negocios sin dañar a las personas? Esto puede alcanzarse si se considera la RSE como eje del trabajo empresarial. Adicionalmente, si esta es entendida a partir de la teoría de los grupos de interés como una aproximación normativa que señala cómo las empresas deben actuar con la sociedad — sean grupos o individuos-, entonces puede considerársela una guía o regulación que deberá tenerse en cuenta para alcanzar una conducta responsable. Finalmente, comprender estas exigencias éticas apunta hacia un tipo de participación del grupo de interés (grupos locales) en la determinación del futuro de la dirección de las empresas.

\section{III.PRINCIPALES CRÍTICAS AL ENFOQUE DE LAS RELACIONES ENTRE CORPORACIONES Y GRUPOS DE INTERÉS}

Desde el enfoque de los grupos de interés que hemos asumido, la RSE considera que los negocios pueden ser influenciados por la sociedad, y que así se puede generar una relación multidireccional de persuasiones hacia la empresa. A partir de esta afirmación, el enfoque considera, además, que las empresas asumen un rol activo y horizontal en su relación

22 Planes, guías, protocolos, etcétera, pueden ser de utilidad para saber cómo seguir las pautas de la RSE. 
con el resto de actores sociales, a partir de lo cual se «descentra» el punto de reflexión sobre lo que la empresa debe hacer. Sin embargo, han sido varios los autores que han generado críticas ante tales aproximaciones: las más importantes consideran que las empresas deben enfocar su trabajo en la generación de ganancia económica más que a satisfacer expectativas sociales, y que en la práctica es muy complicado reconocer con certeza a los grupos de interés, sobre todo a las comunidades locales.

La primera crítica se basa en el argumento de Milton Friedman, Premio Nobel de Economía en 1976, quien considera que la única responsabilidad social que los negocios tienen con la sociedad es la maximización de las utilidades para los accionistas, dentro de los marcos de la ley y de la costumbre ética. Este argumento representa un enfoque de la responsabilidad social empresarial basado exclusivamente en la generación de utilidades. Defiende que las empresas deben relacionarse con la sociedad principalmente sobre la base de las reglas del juego: las reglas del mercado, de la ley y la costumbre ética ${ }^{23}$. Es decir, las acciones de la empresa se deben guiar según estos parámetros solo si ayudan a la generación de utilidades. En tal sentido, la manera cómo las empresas deben relacionarse con la sociedad representa una conducta sostenida en el trabajo rentable, en la obediencia a la ley estatal y en la búsqueda de algunas iniciativas sociales que signifiquen —al ejecutarlas — un incremento en su riqueza. Así, la actuación será responsable cuando beneficie al centro, la empresa, y solo cuando sus intereses se prioricen al del resto de actores con los que se relaciona: el entorno. No se asume un rol de actor en la sociedad debido a un débil involucramiento (rol social pasivo), al estar sostenido solo en el interés personal (self-interest).

No cuento con mucho espacio para presentar extensamente el debate entre los representantes de las posiciones que definen la RSE desde un enfoque basado en los accionistas y las que la definen a partir de los grupos de interés. Sin embargo, presentaré dos razones que considero importantes para rebatir el argumento basado solamente en la generación de ganancia.

La primera de ellas considera que actuar de manera responsable no implica no ser rentable. Las responsabilidades sociales y la generación de ganancia en el corto o largo plazo no pueden ser vistas como irreconciliables. De acuerdo con Trevino y Nelson, «existe un vínculo entre la irresponsabilidad social y la rentabilidad negativa de los mercados de valores $\aleph^{24}$. Por ello, se puede afirmar que las empresas pueden ser rentables y responsables al mismo tiempo ${ }^{25}$.

23 Friedman, M. "The social responsibility of business is to increase its profits». New York Times Magazine, 13 de septiemnre de 1970.

24 Trevino, L. K. y D.A. Nelson. Managing business ethics. Segunda edición. Nueva York: Wiley, 1999. 25 CARROLL, A. "Corporate social responsibility: evolution of a definitional construct». Business and Society, № 38 (3), 1999, pp. 268-295. Adicionalmente, y sobre la base de la afirmación, presentamos a manera de ejemplo dos casos que sirven de sustento fáctico de esta postura: el caso Tylenol y el caso IKEA. En el primero, la empresa Johnson y Johnson se vio envuelta en un problema frente al que tenía que decidir si retiraba del mercado estadounidense a su producto estrella, Tylenol, debido 
La segunda razón considera que la responsabilidad social debe ser entendida como una relación de condiciones mínimas entre las empresas y los grupos interesados. Si la responsabilidad principal del negocio tiene un fin corporativo fiduciario relacionado solamente a los intereses de los accionistas, ello permitiría que las empresas entiendan que se puede hacer negocios en condiciones moralmente censurables ${ }^{26}$. Así, por ejemplo, en una sociedad se podría contaminar porque no existe una regulación adecuada, o se podría practicar un trato discriminatorio hacia la mujer porque las normas legales o las del mercado lo permiten, o porque no las regulan oportunamente o porque no las controlan de manera eficaz, pero ello de ninguna manera implica que una empresa no deba evitar incurrir en dichas prácticas tan solo porque no son parte de giro del negocio. De hecho, este tipo de conductas puede generar reacciones sociales en contra de las empresas y de la manera cómo deciden relacionarse con la sociedad. Aplicar el refrán «Haz en Roma lo que los romanos hacen» no sería justificación suficiente para permitir ciertas prácticas censurables.

Otra crítica importante de la teoría de los grupos de interés se basa en criterios pragmáticos y se concentra en las dificultades relacionadas a la forma de reconocer a estos grupos de manera efectiva, y sobre todo a cómo lidiar con un sinnúmero de intereses y expectativas. En tal sentido, propone que las empresas no deben asumir ciertas responsabilidades porque la identificación de los interesados o afectados puede resultar exigente y ajena al trabajo empresarial.

Según J. Smith, esta afirmación puede ser cierta; sin embargo, el autor sostiene que «[...] los teóricos de la teoría de stakeholders han proporcionado muchos algoritmos para el trato y la identificación de los grupos de interés» ${ }^{27}$. Además, un conjunto de metodologías y herramientas prácticas han sido desarrolladas para mejorar la forma en que las empresas pueden reconocer los intereses de los grupos con los que se relacionan. De hecho, en su libro Strategic Management: a Stakeholder Approach,

a que en Chicago, en 1984, varias personas fallecieron por ingerir pastillas de cianuro que habían sido introducidas en los envases de este producto. El dilema se presentó porque retirar el producto del mercado significaría pérdidas millonarias para la empresa (Tylenol poseía en ese momento el $37 \%$ del mercado de pastillas de venta libre sin receta), frente a mantener la confianza en sus clientes. La empresa decidió retirar el producto y, luego de dos meses, lo reinsertó al mercado, lo cual sucedió con bastante éxito, no solo porque su imagen no se vio dañada, sino porque se pensó que la seguridad de sus clientes era lo más importante para continuar con el negocio. Por otro, IKEA es una empresa sueca que se dedica a la venta de muebles para armar, entre otros productos para el hogar. A mediados de la década de 1980, se demostró que varios de sus muebles de madera excedían los límites daneses establecidos para el uso de formaldehido —un gas inflamable y venenoso empleado para fabricar colorantes e insecticidas-. Como consecuencia, la empresa - luego de una serie de cuestionamientos - decidió que las consideraciones ambientales podrían afectar su credibilidad futura. Por ello, luego de reducir la presencia del gas en sus barnices para muebles, y junto con varias organizaciones sociales —entre ellas Greenpeace_-implementó el Plan Paso Natural, un plan de acción ambiental en el que se describen medidas para reducir al mínimo el impacto ambiental negativo de sus actividades, entre otras acciones.

26 WERHANE, P.H. «The moral responsibility of multinational corporations to be socially responsible». En HOFFMAN, W. et. al (editores). Emerging global business ethics. Connecticut: Bentley College, 1994, pp. 136-142.

27 SMITH, J. «The shareholders vs. stakeholders debate». Óp. cit., p. 86 (traducción propia).

EL DIÁLOGO EN LA IMPLEMENTACIÓN

DE NORMAS DE

RSE COMO PRO-

MOTOR DEL EJER-

CICIO ADECUADO

DE DERECHOS: UN

ENFOQUE A PARTIR

DE LA ÉTICA DEL

DISCURSO DE JÜR-

GEN HABERMAS 
Freeman plantea que el enfoque de los grupos de interés necesita del desarrollo de procesos y técnicas para mejorar la capacidad de gestión corporativa con las partes interesadas ${ }^{28}$. Así, propone un marco o una guía para gestionar las relaciones corporativas con las partes interesadas. Reconocer e identificar los intereses y las expectativas de los grupos de interés, si bien es un trabajo complejo, no representa un objetivo imposible de cumplir.

Algunas empresas extractivas han sido cuestionadas porque, en lugar de considerar el argumento de Freeman, se han concentrado en las dificultades para identificar las expectativas de los grupos locales, así como los propios grupos, cuando llevan a cabo su trabajo. Muchas podrían argumentar que algunos impactos considerables son permitidos por la ley - tal es el caso de la discusión acerca de los límites máximos permisibles-y que ellas actúan siguiendo lo que está establecido legislativamente. Sin embargo, estas acciones amparadas en la ley —que obviamente se pueden considerar reprobables debido a sus negativos impactos- no justifican la inacción. Trasladar la responsabilidad exclusivamente hacia Estado representa una mirada limitada de los niveles de responsabilidad social. Actuar de esta manera generaría un clima de desconfianza hacia la empresa extractiva, dado que demuestra un accionar contrario a lo que se espera como adecuado para y por la sociedad y los grupos locales.

Por ello, y retomando el modelo de Carroll, hacer solo lo que la ley dice no es RSE sino solo una parte de esta, ya que falta identificar qué hacer y cómo hacerlo considerando lo que la sociedad espera y desea (responsabilidades éticas y filantrópicas). Eso sí: como parte de este trabajo de identificación, las empresas no deben confundir las demandas sociales cuestionables o manipuladas con lo que realmente se considera importante para generar convivencia y bienestar social ${ }^{29}$.

\section{DESARROLLO DE LAS RELACIONES CON LOS GRUPOS DE INTERÉS}

Las distintas formas como las empresas consideran las expectativas y los reclamos sociales en sus procesos de toma de decisiones apuntan a considerar a los posibles afectados en la manera cómo llevan a cabo sus operaciones ${ }^{30}$. Pero, para ello, es necesario establecer un proceso de diálogo con un espectro amplio de partes posiblemente involucradas ${ }^{31}$, entre ellas, las comunidades locales. Según Morsin y Schultz:

La teoría de los grupos de interés ha desarrollado un enfoque basado en la importancia del involucramiento de estos grupos en la creación de 
valor a largo plazo (Andriof et. al. 2002). Este es un proceso cuya perspectiva se centra en el desarrollo de una relación mutua a largo plazo en lugar de centrarse simplemente en un beneficio inmediato. No implica que el beneficio y la supervivencia económica no sean importantes, sino que se argumenta que, con el fin de obtener ganancias y sobrevivir, las empresas con frecuencia tienen que emprender relaciones sociales con una variedad de grupos de interés de quienes depende ${ }^{32}$.

Una serie de relaciones diferentes de la empresa en la red social representa la interacción entre estas y una gran diversidad de interlocutores sociales. Dichas relaciones deben centrarse en un mutuo y relacional compromiso empresarial, a partir de un punto de vista interactivo (diálogo) que pueda generar las bases para la rendición de cuentas (accountability) del cumplimiento o no de la satisfacción de las expectativas sociales ${ }^{33}$. Así, como complemento para el desarrollo de las relaciones con los stakeholders, y porque se necesita encontrar un equilibrio entre las preocupaciones y reclamos de las partes interesadas y de la propia empresa, es necesario que estas últimas tengan la voluntad de reconocer y abordar abiertamente los conflictos potenciales que se puedan generar (RSE como acción).

Sin embargo, ipor qué las empresas extractivas deben considerar de manera especial su relación con los grupos o comunidades locales? Simple: debido a que estas corporaciones tienen el poder suficiente para generar diferentes tipos de impactos sobre comunidades locales que podrían cambiar drásticamente la forma en que han vivido. En otras palabras, la comunidad local espera que, si una empresa extractiva tiene que trabajar para ser rentable, entonces su trabajo no debe generar impactos negativos que afectan su vida de forma dramática. De la misma manera, las empresas pueden desempeñar un papel importante en el desarrollo de la comunidad. La afectación sería positiva en tanto que puede fortalecer las capacidades de los miembros de las comunidades. Por ejemplo, pueden crear puestos de trabajo para los miembros de la comunidad, interactuar con otras empresas más pequeñas o contribuir con los servicios de salud local. Como resultado, las empresas generan impactos positivos y negativos, que deben poder ser previstos y manejados adecuadamente, sobre las comunidades locales.

En ese sentido, el diálogo representa la base práctica sobre la cual las empresas pueden erigir sus decisiones y acciones, así como la cocreación de conocimiento compartido entre ellas y las partes interesadas. Por eso, si la RSE se basa en las expectativas de los interesados, tal debe considerar la práctica del diálogo con las partes interesadas con el objetivo de conocer esas expectativas para alcan-

32 MoRsING, M. y SCHULTZ, M. «Corporate social responsibility communication: stakeholder information, response and involvement strategies». Business Ethics: A European Review, vol. 15, № 4, 2006, pp. 324-325 (traducción propia).

EL DIÁLOGO EN LA IMPLEMENTACIÓN

DE NORMAS DE

RSE COMO PRO-

MOTOR DEL EJER-

CICIO ADECUADO

DE DERECHOS: UN

ENFOQUE A PARTIR

DE LA ÉTICA DEL

DISCURSO DE JÜR-

GEN HABERMAS 
zar una mejora en la convivencia. Las preguntas ahora son por qué y cómo el diálogo con las partes interesadas puede mejorar la RSE, lo cual intentaremos abordar siguiendo la teoría de la ética discursiva de Jürgen Habermas.

\section{PERFECCIONAMIENTO EN LA PRÁCTICA DE LA RSE COMO RESULTADO DEL DIÁLOGO CON LOS STAKEHOLDERS: UN ENFOQUE A PARTIR DE LA ÉTICA DEL DISCURSO DE HABERMAS}

El objetivo aquí es presentar un argumento basado en la posición de Habermas con respecto a cómo mejorar el marco de la RSE a través del diálogo con las comunidades locales. Para ello, se reflexionará acerca de las ideas del filósofo alemán con relación a la ética del discurso y a la actitud dialógica ${ }^{34}$.

Nuestra primera afirmación es que la RSE representa un marco normativo que guía cómo las empresas deben interactuar con los grupos de interés. La segunda es que la RSE representa cómo se toman en cuenta las expectativas sociales cuando se interactúa con la población. En ambos casos, hemos focalizado el debate en torno a las empresas extractivas y a las comunidades locales cercanas a su área de influencia directa. Adicionalmente, consideramos que el marco referencial de la RSE solo será aceptable para alcanzar su fin si es que:

- las partes interesadas consideran que sus expectativas sociales son o fueron consideradas en la discusión, la elaboración y la implementación del marco de la RSE; y

- las empresas consideran oportuna y adecuadamente las expectativas sociales en el marco de la discusión, la elaboración y la implementación de sus políticas de RSE.

En el caso de las empresas extractivas, la RSE sería aceptable como significativa para guiar la interacción entre estas empresas y las comunidades locales, solo si ellas consideran tanto la búsqueda de la utilidad como lo que las comunidades locales creen importante al evitar los impactos negativos de la actividad productiva o del giro del negocio. La pregunta inicial es, ¿cómo se sabe ello?

Diversos autores consideran la RSE debe ser elaborada y luego implementada mediante el ejercicio del diálogo. En otras palabras, el diálogo se convierte en una herramienta capaz de facilitar el saber qué esperan las comunidades locales y evaluar ciertas expectativas dentro de la cadena de negocio. Sin embargo, ¿qué significa dialogar? ¿Cuáles son sus 
condiciones? Aquí haremos uso de lo que se conoce como ética normativa del discurso ${ }^{35}$.

En primer lugar, cabe resaltar las premisas conceptuales de esta aproximación filosófica. Jürgen Habermas busca continuar el trabajo del filósofo alemán Immanuel Kant sobre el siguiente aspecto práctico: icómo se debe actuar? ${ }^{36}$ Ambos autores tratan de proponer una teoría ética basada en normas y principios que apoyan las acciones humanas. Para ello, Habermas sugiere la idea de un marco normativo que puede fundamentar la siguiente premisa de acción: cómo deben actuar los seres humanos. Argumenta que tales normas serán la base y la motivación de la acción social humana. En otras palabras, como parte de la interacción humana, las normas que regulan la forma en que las personas deben comportarse (interacción) están basadas en un marco que todos pueden aceptar como válido para guiar su conducta.

Sin embargo, estas normas requieren dos condiciones: deben basarse principalmente en un discurso racional entre las personas y deben ser aceptadas como válidas por tales individuos antes de decidir cómo comportarse. Entonces, icómo entiende Habermas la idea de discurso racional entre individuos? ¿Y cómo pueden estas normas ser aceptadas por la gente para — sobre la base de ellas— actuar?

De acuerdo con Habermas, las normas para la acción son el resultado de una situación ideal de conversación o discurso entre las personas. En esta situación ideal de habla, la gente discute las normas que deben regir sus acciones. Para alcanzarlas, los participantes van presentando las razones que sustentan por qué estas deben orientar su conducta. Tales normas deberán ser el resultado del ejercicio deliberativo, cuyo objetivo final es que la gente esté de acuerdo (consenso) con respecto a cómo las normas guiarán la forma en que deben actuar. Luego la aceptación de lo acordado (normas de conducta) se considerará como obligatorio porque los participantes formaron parte de la discusión de la elaboración normativa. En otras palabras, la gente respeta y sigue la norma - la consideran válida - porque comprenden su fin, dado que fueron parte de la discusión de su elaboración.

Habermas denomina a esta situación ideal diálogo o argumentación racional. Considera que los participantes en este son seres racionales ${ }^{37}$ porque cuentan con competencias comunicativas que les permiten discutir entre ellos. Dichas competencias son algo más que conocimientos básicos de un idioma determinado o de su vocabulario. Refieren un tipo de

$35 \mathrm{Al}$ respecto, véanse estas tres obras de Jürgen Habermas: Aclaraciones a la ética del discurso. Madrid: Editorial Trotta 2000; Moral consciousness and communicative action. Cambridge: Polity Press, 1990; y Escritos sobre moralidad y eticidad. Barcelona: Paidós, 1991.

36 De acuerdo con Habermas, toda ética normativa tiene que ser capaz de brindar un principio que, básicamente, permita un acuerdo racionalmente motivado, conseguido cuando se discutan cuestiones morales prácticas. Véase HABERMAS, Jürgen. Aclaraciones a la ética del discurso, 2000. Disponible en <http://www.ucm.es/info/eurotheo/habermas.htm>.

37 Según Habermas, un ser racional es un ser humano. L. cit. 
disposición para hablar, que se basa en el dominio para involucrarse en la situación ideal a través del uso de la argumentación. Es decir, los participantes son racionales porque son capaces — condición propia y única del participante- de usar la argumentación para expresarse a través de la comunicación. Así, comprenden y comparten la importancia de la cuestión que está en discusión porque tienen la capacidad para hacerlo.

Debe tomarse en cuenta, además, que los oradores/participantes no solo pueden comunicarse a través de la argumentación, sino que también deben tener la voluntad de discutir (deliberar). En el diálogo, los participantes están dispuestos a hablar, afirmar, defender, mostrar ideas, cuestionar y entender los argumentos y las posiciones normativas que sostienen posturas y puntos de vista. Se considera así que los participantes cuentan con una disposición a la deliberación y a alcanzar sus fines (voluntad).

La argumentación, por ello, es la herramienta que las partes implicadas en el diálogo utilizan para dar razones y, a su vez, convencer a los demás. En ese sentido, el diálogo basado en la argumentación implica que los participantes no deben manipular, sino convencer o persuadir, basados en el uso de argumentos racionales. Pero, como condición previa, aunque los participantes sean capaces de presentar razones, deberán estar motivados por el deseo de llegar a un consenso (el fin de la deliberación). En ese sentido, el consenso no es solo el resultado del diálogo, sino también su motivación. Sin embargo, para lograrlo, cada participante debe considerar el interés común, mas no intereses particulares. Por lo tanto, un diálogo es un proceso de comunicación entre las personas que pueden discutir y llegar a un consenso mediante la persuasión entre ellos, y se basa en la capacidad de elaborar los argumentos desde una motivación ajena al interés individual. Aunado a lo dicho, B. Endress considera $^{38}$ además que este tipo de diálogo presenta otras condiciones para la deliberación participativa:

- Los participantes evitan contradecirse y hacen uso consistente del significado de las expresiones. Es decir, pueden y deben exponer razones sólidas.

- En la argumentación, los participantes se alejan de su punto de vista personal y consideran de manera crítica la cuestión en discusión. Es decir, deben tomar una posición objetiva en su motivación a la deliberación.

- El contexto político de la argumentación requiere que los participantes intervengan libremente con un auténtico sentido de la igualdad. Es decir, participan por ser iguales. 
De este modo, se puede afirmar que los participantes en el diálogo no solo son capaces de presentar razones, sino que estas deben ser sólidas, elaboradas desde una posición hipotética u objetiva. Asimismo, pueden discutir entre ellos sin restricciones personales basadas en particularismos que los diferencien y que les impidan involucrarse, dado que no se habla de personas particulares, sino de razones posibles de ser entendidas por todos (universalidad del discurso). Por eso, Habermas define esta situación como la representación de una comunidad de pares iguales. Surgen luego, a partir de lo descrito, dos preguntas: iqué significa asumir una posición hipotética u objetiva? y, icuál es la idea de Habermas de una comunidad de pares iguales?

Habermas entiende una situación hipotética de acuerdo a las etapas del desarrollo moral de Lawrence Kohlberg ${ }^{39}$. Este autor ${ }^{40}$ plantea, desde la psicología, que los seres humanos desarrollamos nuestras capacidades morales como parte de nuestra conducta social. Pasamos por estadios o etapas de desarrollo a partir de momentos biológicos, es decir, de edades cronológicas. La tercera etapa de desarrollo moral — denominada post-convencional - implica que el razonamiento moral se basa en la consideración para la acción de la conducta social de una serie de principios universales. En esta etapa, todos somos capaces de ir más allá de las necesidades personales (fase pre-convencional) y el solo respeto a la norma por serlo (fase convencional) para pensar los problemas morales de manera abstracta: en otras palabras, somos capaces de asumir una posición que es potencialmente universal. Los participantes en el entendimiento moral pueden hacerlo tomando en cuenta las reglas de la lógica, las normas y su propia forma de vida de manera hipotética. Es decir, para Habermas, los participantes en el diálogo deben y pueden asumir una posición descentrada —o sea, dejar de pensar de manera individual, fuera del propio centro- que les permite entender con objetividad las razones de su acción.

Con esta actitud, nuestras creencias acerca de los objetos, de las relaciones sociales y del conocimiento personal pueden ser suspendidas para considerar que el razonamiento sobre la norma es lo que debe primar

39 HABERmAS, Jürgen. Aclaraciones a la ética del discurso. Óp. cit., pp. 83-105.

40 De acuerdo con L. Kohlberg, podemos comprender el desarrollo moral de una persona según la forma en que sostiene/defiende/justifica sus posiciones morales a través del uso de la argumentación. En ese sentido, la argumentación puede aclarar la comprensión de la acción moral al brindar sentido al porqué de dicha acción. Para demostrarlo, Kohlberg sostiene que el desarrollo moral tiene tres estadios. Cada uno representa la base sobre la cual una persona puede explicar su acción moral. En el primer estadio (pre-convencional), la gente centra su decisión moral en una posición egocéntrica. Así, elaboran argumentos que justifican acciones morales de acuerdo a un temor a recibir un castigo si no se hace lo correcto, o para obtener algún premio como resultado de su decisión. En el segundo estadio (convencional), las razones para la acción moral son elaboradas a partir de reglas sociales o legales, normas que debemos seguir por su condición de tal. Sin embargo, no se cuestiona lo justo de la norma, sino que se acepta en tanto tal. En la tercera fase o estadio (post-convencional), Kohlberg considera que las personas superan los dos estadios anteriores y que son capaces de justificar sus acciones morales desde una posición objetiva, teniendo en cuenta para ello una serie de valores y principios universales que no se centran en la figura individual. En esta etapa, el individuo justificará sus acciones tomando en cuenta principios que cualquier persona pueda entender y compartir, sin considerar intereses particulares (egocéntricos) o la sola existencia de una norma convencionalmente aceptada.

EL DIÁLOGO EN LA IMPLEMENTACIÓN

DE NORMAS DE

RSE COMO PRO-

MOTOR DEL EJER-

CICIO ADECUADO

DE DERECHOS: UN

ENFOQUE A PARTIR

DE LA ÉTICA DEL DISCURSO DE JÜRGEN HABERMAS 
en la deliberación. Además, desde una posición descentrada, se puede asumir la posición de los demás participantes de manera hipotética (ejercicio empático). En ese sentido, Habermas afirma que todos los participantes en el diálogo racional son capaces de asumir tanto las razones de lo que se discute como el punto de vista de todos los demás afectados por la norma en cuestión -incluso a pesar de diferencias socioculturales existentes_- ${ }^{41}$.

Por otra parte, el filósofo considera como comunidad de pares aquella en la que los participantes son considerados iguales. Ello es así por dos razones. La primera considera que los participantes poseen las mismas oportunidades y capacidades para involucrarse en la deliberación dialógica. La segunda considera que, en tanto poseen la condición de persona humana, deben ser tratados con respeto. Y como los que participan son humanos y poseen capacidades para la deliberación, su involucramiento y participación tiene lugar en las mismas condiciones, sin mediar diferencias en el plano del diálogo. Todas las personas son capaces de participar en la discusión de aquellas normas que apuntan a regir su conducta (equidad y justicia).

Sin embargo, es importante señalar que el papel de los participantes en el diálogo debe ser voluntario. Esto significa que los participantes deben tener la voluntad y la disposición para participar en la elaboración de normas que podrían regir su conducta (autonomía volitiva). Como resultado, todos los participantes aceptan las normas discutidas, ya que formaron parte de la deliberación en las mismas condiciones, sin existir coerciones. A partir de ello, nos surgen dos ideas alrededor de lo explicado:

- La norma es el resultado del consenso, pero debe representar el resultado de la discusión entre personas que estén en igualdad de condiciones y oportunidades para participar en su búsqueda.

- Para seguir y aceptar como válidas las normas de acción, los participantes del diálogo deben reconocer que las normas se hicieron para ellos y no contra ellos.

La norma final para la acción no solo deberá ser el resultado de un consenso, sino que además debe expresar el entendimiento mutuo de todos los participantes en la deliberación racional. En ese sentido, las normas de acción representarán los intereses de todo el grupo —un interés generalizable/universal — para que se considere válida. Así, la norma para la acción será válida — y universal- para todos en tanto representa los intereses comunes o posibles de ser generales de todos los potencialmente afectados por dicha norma, quienes a su vez participaron en su elaboración. D. Reed sostiene ${ }^{42}$ que las normas válidas poseen dos atributos: 
- Atributo 1. Las normas válidas para la acción se elaboran como resultado de un consenso racional de diálogo en el que todos los afectados por ellas son capaces de participar.

- Atributo 2. Dado que tales discursos involucran interpretaciones de los participantes y solo se pueden resolver sobre la base del consenso, cualquier norma de acción válida debe representar un interés generalizable.

Las normas de acción así serán aceptadas como válidas ya que cuentan con la aprobación de todos los participantes — quienes son los posibles afectados por tales normas - que estuvieron involucrados en su elaboración, mediante el empleo de un discurso práctico cuyo resultado representa, además, los intereses de todos ellos ${ }^{43}$. Además, de acuerdo con Habermas, el discurso racional o diálogo necesita de una condición especial o principio subyacente a la comunicación entre los participantes. Este principio resume lo explicado y es, a su vez, la fuente de cualquier construcción ética normativa. La formulación de esta condición normativa se denomina Principio de la Ética del Discurso (Principio D): «Sólo pueden pretender validez aquellas normas que puedan contar con el asentimiento de todos los afectados como participantes de un discurso práctico» ${ }^{44}$.

Resumiendo, Habermas considera que una norma para la acción será válida para toda una comunidad de personas (racionales) si se establece como resultado de una deliberación racional (o diálogo) entre ellos. Las personas que puedan verse afectadas por una norma de acción deben y pueden participar en el debate de su elaboración porque son capaces de entender y compartir las razones que apoyarán luego su debido cumplimiento. Además, las normas como resultado de esa deliberación deberán representar un interés generalizable alcanzado a través de la comprensión de lo deliberado por todos los participantes —normas «universalizables» para quienes formaron parte de su elaboración — sin coacción alguna. Por lo tanto, el diálogo representa la manera en que la gente puede estar de acuerdo sobre cómo deberían (inter) actuar, lo que a su vez permite la validez de la norma en el contexto de su aplicación en tanto representación de los intereses de los participantes ${ }^{45}$.

Cotidianamente, el diálogo en la sociedad no representa esta situación ideal. Ello no deberá, sin embargo, descartar que la comprensión de este ideal — cómo debe ser el diálogo — no pueda representar un punto de partida que, al mismo tiempo, se pueda considerar una guía para perfeccionar la interacción entre las personas. De tal modo, la siguiente

EL DIÁLOGO EN LA IMPLEMENTACIÓN

DE NORMAS DE

RSE COMO PRO-

MOTOR DEL EJER-

CICIO ADECUADO

DE DERECHOS: UN

ENFOQUE A PARTIR

DE LA ÉTICA DEL DISCURSO DE JÜRGEN HABERMAS 
pregunta nos es de utilidad para los fines de nuestro trabajo: icómo podemos aplicar el enfoque de Habermas para mejorar la relación entre las empresas extractivas y las comunidades locales?

Como mencioné antes, la RSE representa un marco (ético) normativo que guía la forma en que las empresas deben interactuar con los grupos de interés. Asimismo, consideramos que la RSE resume cómo se toman en cuenta las expectativas sociales cuando se interactúa con la población. Sobre la base de ello, elaborar marcos o guías de RSE necesariamente requiere saber cuáles son las expectativas sociales que deberían ser consideradas como lo que se debe hacer (manera de actuar) o lo que se debe considerar (conducta) cuando se trabaja. Ello representa recoger tales expectativas a través de un constante interactuar con diversos grupos de interés y utilizar el dialogo como herramienta para lograrlo. No nos interesa volver a afirmarlo, sino saber cuáles son las condiciones necesarias sin las que tal deliberación —en la elaboración de los marcos de RSE— se vería debilitada.

A partir de lo que Habermas propone, podemos afirmar que el rol del diálogo en la RSE — tal y como lo hemos ido revisando- implicará la herramienta relacional a tener en cuenta entre la empresa y sus grupos de interés — como parte de una red social- que permita que todos los posiblemente afectados por las acciones de la empresa puedan participar en el debate de la elaboración del marco de acción (RSE). En otras palabras, para aceptar la RSE como válida o importante para guiar la interacción con la sociedad, las expectativas no solo deben ser consideradas en la discusión para su elaboración, sino que deben reconocerse y recogerse basándose en el diálogo con los stakeholders. En el caso de las empresas extractivas, la RSE será válida para guiar la relación entre la empresa y las comunidades locales si se establece como consecuencia del diálogo con estos grupos, cuyos intereses están relacionados a la no generación de cambios dramáticos en su manera de vivir. Como resultado de ello, se conseguirán normas para un comportamiento responsable en esta interacción, normas que serán consideradas válidas por los niveles de participación registrados durante su construcción - los posiblemente afectados por normas de acción deben sentir que tales fueron elaboradas por ellos (o con ellos) y no en contra de ellos-.

Siguiendo el enfoque de Habermas, los actores de la elaboración de la RSE deben motivar su participación en la disposición a discutir/deliberar sobre cómo deberían guiar su relaciones intersubjetivas. En ese sentido, para llegar a un consenso, los grupos de interés y las empresas, en tanto participantes en la elaboración de las líneas de la RSE, deben admitir disposición al diálogo, a dar razones y a asumir una posición que tienda hacia el consenso y el beneficio para todos. Además, deben compartir un entendimiento mutuo con respecto a la forma en que deben orientar su interacción. La RSE luego representará, en lo posible, un interés generalizable. 
Y entendida como un interés generalizable a las partes involucradas o posiblemente afectadas por las actividades empresariales, la RSE representa un equilibrio a alcanzar en el proceso deliberativo de la elaboración normativa. Este equilibrio contendrá: (1) las expectativas sociales de los grupos de interés — por ejemplo, la comunidad local—; (2) lo que se considera importante para la empresa — la búsqueda de sus fines—; y (3) la suposición de que este resultado o guía será la norma para la interacción entre las empresas y sus stakeholders. En ese sentido, el resultado de una discusión/deliberación entre las empresas y sus grupos de interés deberá tener como fin un interés común o generalizable, representado en una guía o política de RSE consensuada y validada entre ellos.

Sobre la base de lo explicado hasta el momento, podemos afirmar entonces que las empresas - para nuestro caso, las extractivas-y los grupos de interés — principalmente los grupos o comunidades locales- deben deliberar - a través del diálogo- para obtener por consenso las premisas sobre las cuales se construya una guía o política de RSE — es decir, un marco ético normativo sobre el cual la empresa determina cómo trabajar considerando las expectativas sociales-. Por ello, entre empresas extractivas y comunidades locales, cuanto mayor nivel de consenso sobre cómo actuar (RSE), mayores niveles de confianza entre las partes, lo cual permitirá conseguir la licencia social que sirva de garantía para los fines de la empresa y la mejora de la calidad de vida de los posibles afectados por sus actividades.

Complementario a lo anterior, debido a que todos los participantes en la elaboración de marcos de RSE poseen la misma capacidad de exponer sus argumentos, la RSE será el resultado de la argumentación y la persuasión para llegar a un marco de consenso. Además, como parte de sus capacidades racionales y humanas, los participantes en este diálogo podrán ocupar una posición de descentramiento de sus razones y asumir el punto de vista de los demás participantes (capacidad empática).

Permítanme suponer a manera de ejemplo que una empresa extractiva debe mover una montaña para explotar el recurso que se encuentra en su interior, y que las comunidades locales que viven cerca de la montaña no quieren perder sus tierras como resultado de este interés empresarial específico. Ambas partes tendrán que ponerse de acuerdo sobre la forma en que la empresa debe actuar para no afectar negativamente los medios de subsistencia de las comunidades locales.

Supongamos ahora que la empresa, antes de llevar a cabo sus acciones, elaboró una política de RSE. Dicho marco de acción ayuda a que esta y las comunidades locales que puedan ser afectadas por sus operaciones - extracción del mineral previo traslado de habitantes cercanos a la montaña, por ejemplo_- puedan alcanzar niveles de acercamiento que generen confianza para la convivencia —es decir, que la empresa obtenga ganancias y que los miembros de la comunidad local vean sus

EL DIÁLOGO EN LA IMPLEMENTACIÓN

DE NORMAS DE

RSE COMO PRO-

MOTOR DEL EJER-

CICIO ADECUADO

DE DERECHOS: UN

ENFOQUE A PARTIR

DE LA ÉTICA DEL DISCURSO DE JÜRGEN HABERMAS 
vidas menos afectadas cuando ello ocurra- Resulta entonces imperativo que, tanto para la elaboración de los marcos de RSE como para la concreción de la movilización de la montaña - llevar a cabo una acción del giro del negocio tomando en cuenta lo que la empresa considera como líneas de RSE_-, ambas partes deben estar dispuestas, antes de la negociación, al diálogo; asimismo, deben compartir un deseo de mostrar buenas razones para justificar sus expectativas, como ejes de la acción y herramientas prácticas de la concreción. En otras palabras, sin disposición para dialogar, sin entender la importancia de la herramienta dialógica y sin comprender la real naturaleza normativa de la RSE como filosofía corporativa - hacer lo que la sociedad espera que se haga-, no se pueden conseguir buenos marcos de RSE para la acción ni niveles de confianza y validez entre los posiblemente afectados y la empresa. El diálogo permite que las líneas de RSE sean validadas y, por ello, consideradas la base sobre las cuales actuar para alcanzar los fines del negocio (extracción), antes preguntándose cómo conseguirlos sin generar daños a terceros.

Las empresas y los interesados deberán encontrar un equilibrio entre sus diferentes intereses para lograr un posible consenso que apoye su interacción. Es decir, las partes implicadas en el diálogo deben hallar lo que consideran un interés común entre lo que ambos desean obtener. Por ejemplo, algunas cuestiones en el proceso de diálogo del ejemplo podrían ser: (1) que la sociedad considere los intereses de las comunidades locales como significativos en el momento de la toma de decisiones empresariales, con el objetivo de no generar daño, si es que no sucediese así; o (2) encontrar una idea que guíe y fortalezca la relación entre la empresa y las comunidades, a pesar de la posibilidad de que estas últimas se tengan que alejar de sus tierras.

A partir de lo señalado, la RSE debe mostrar la comprensión mutua con respecto a cómo las empresas deben actuar considerando las expectativas sociales en su desempeño, así como la asunción de sus responsabilidades. Para ello, la herramienta es el diálogo, entendido desde la propuesta de Habermas. Conseguir aplicar un verdadero diálogo genera la posibilidad de tener un contexto construido que no solo acerca a las partes interesadas sino que se convierte en el escenario propicio para procesos de negociación.

Por otro lado, la idea de comunidad de pares explicada por Habermas nos permite comprender que los posibles afectados por las normas de acción (RSE) pueden participar en su elaboración, ya que disponen de condiciones para involucrarse en ello. Sin embargo, como fue el caso de la noción de la situación ideal, la idea de comunidad inter-pares es otro punto de partida de algo que todavía no ocurre completamente en la realidad —el trato igualitario o con equidad—, pero que se percibe como lo distintivo de lo que hace posible una mejor interacción entre 
las personas. El acápite siguiente retomará este punto, considerando que solo entre los iguales se reconocen derechos y deberes.

No obstante, es importante antes señalar que el ideal de la comunidad de pares es lo que tiene que rescatarse y considerase como principio a seguir en la elaboración de los marcos de RSE. Esto se puede representar de la siguiente manera: en la consolidación de una real ciudadanía corporativa, el principio de respeto mutuo a los stakeholders debe considerarse como fundamento de la acción de RSE. Así, la percepción de que las empresas y los grupos de interés pueden participar libremente y con un sentido de igualdad en la elaboración de la RSE significa que las partes participen basándose en el respeto mutuo y en el respeto a la condición de persona. En ese sentido, los marcos normativos de RSE son «CO-construidos» entre las empresas y sus interlocutores en un trato en igualdad de condiciones donde los aportes son válidos por sí mismos en tanto apunten a conseguir el interés generalizable. Esto representará la participación de los interesados en la toma de decisiones y la aceptación de negociaciones periódicas con ellos: aceptar que existe cierto nivel de influencia externa en la manera cómo la empresa debe establecer sus guías de RSE ${ }^{46}$. Según Morsing y Schutlz, las empresas no solo influyen sino que también son influenciadas por las partes interesadas, y por lo tanto cambian en el largo plazo — cuando sea necesario- a partir de lo que la sociedad espera ${ }^{47}$.

Uno de los puntos más destacables en la discusión sobre la RSE debe considerar que el diálogo con las partes interesadas no equivale solamente a manipular o a brindar información: deberá entenderse que es un proceso de influencia y de gestión multidireccional, basado en la capacidad para saber oír y saber decir. Adicionalmente, el diálogo exigirá el compromiso y la comprensión mutuas como fundamentos del trato entre los interlocutores, que lleven a un proceso constante de aprendizaje entre los participantes ${ }^{48}$. En ese sentido, los interesados no deberán ser tratados como medio para un fin (rentabilidad o generación de ganancia), sino como un grupo que debe participar en las decisiones que puedan afectarles (fines en sí mismos).

Otro punto que genera cuestionamientos considera, desde una perspectiva escéptica, la dificultad para hablar con personas de diferentes culturas, idiomas y habilidades sociales a partir de la manera en que Habermas entiende dialogar. En la relación de las empresas extractivas con las comunidades locales —en varios casos, rurales-, las empresas deben identificar sus diferentes responsabilidades, así como a las comunidades locales que rodean sus operaciones — siguiendo los modelos de Carroll y Freeman-. Si las empresas extractivas pueden identificar las diferentes partes y sus intereses, entonces pueden darse cuenta también de que

EL DIÁlOGO EN LA IMPLEMENTACIÓN

DE NORMAS DE RSE COMO PROMOTOR DEL EJERCICIO ADECUADO DE DERECHOS: UN ENFOQUE A PARTIR DE LA ÉTICA DEL DISCURSO DE JÜRGEN HABERMAS 
las comunidades locales cuentan con características particulares. Las empresas deben tener en cuenta que los grupos posibles de identificar son diferentes. Como un hecho, la mayoría de las comunidades locales son social y culturalmente diferentes de las personas que trabajan en las operaciones mineras. Eso no se puede negar, sino que es algo que debe afirmarse siempre. Por ello, estas diferencias deben ser consideradas en el momento de entrar en diálogo. Además, cualquier tipo de relacionamiento debe considerar la diferencia como base de la igualdad de trato - reconocimiento de la diversidad y de la pluralidad-. Y como ya lo señalamos, existen metodologías que consideran el reconocimiento de estos grupos de interés y sus características como potenciales, por lo que su consideración se sostendrá a partir de una real voluntad para su inclusión en las lógicas de acción.

Dentro de las líneas expuestas, los participantes deben reconocer la existencia de diferentes intereses, puntos de vista e intenciones que podrían ser parte de la discusión, y tratar de encontrar un equilibrio entre ellos. Aunque la disposición para el diálogo es necesaria para hablar y llegar a un consenso, se puede suponer que las partes implicadas tienen sus propios intereses particulares como fundamentos de su motivación. Así, en la interacción entre las empresas extractivas y las comunidades locales, es posible hallar, por ejemplo, intereses económicos que guían la intención de los debates o la persecución de fines particulares, combinados con una conducta conducida por el bienestar común. En ese sentido, los intereses económicos y las expectativas sociales estarán presentes en el diálogo, lo cual no puede negarse: al contrario, debe pensarse en la RSE considerando esta posibilidad.

En resumen, como resultado del diálogo con las partes interesadas, la RSE no es una situación ideal; es la forma en que las empresas pueden mejorar la forma en que interactúan con la sociedad. El hecho de que esta situación planteada desde Habermas sea un ideal no implica que las ideas de la comprensión mutua y del consenso pragmático sean imposibles. Por el contrario, supone que los seres humanos pueden comunicarse entre ellos y que, como resultado, pueden lograr consensos a partir de un verdadero diálogo.

El propósito del diálogo en la elaboración de marcos de RSE es lograr la comprensión mutua con respecto a cómo las empresas deben orientar sus relaciones con la sociedad sobre la base de acuerdos de consenso. En este proceso, el diálogo se entiende a partir de la participación de todos los que están posiblemente afectados por la RSE —entre ellas, las comunidades locales - para construir marcos de consenso que guíen sus interacciones. Y, en el caso de las empresas extractivas, es alcanzar niveles de convivencia sobre la base de la confianza y de la construcción del desarrollo mientras que son rentables. 


\section{PARA CONCLUIR: COMUNIDAD DE PARES} IGUALES IMPLICA EJERCICIO DE DERECHOS

Luego de presentar los fundamentos éticos, racionales y formales de la RSE a partir de un enfoque de stakeholders para sostener la importancia de un verdadero diálogo entre empresas y grupos locales, corresponde plantear lo siguiente: solo en un escenario donde las partes se ven como iguales se garantiza un efectivo ejercicio de derechos y deberes.

Para empezar tomamos en consideración la noción de comunidad de pares planteada por Habermas en la fundamentación de su ética del discurso. Señalamos que como parte de la fundamentación sobre cómo implementar marcos de RSE para la acción empresarial se hace necesario hacerlo a partir del diálogo con los stakeholders, pero reconociendo además en ellos una necesaria condición de igualdad.

Según lo presentado hasta el momento, en la construcción de los marcos de RSE las partes deben tratarse como iguales en tanto poseen las mismas capacidades y oportunidades para la deliberación. Ello supone un trato en igualdad de condiciones entre los participantes. Pero reforcemos esta idea, dado que requiere de un mayor fundamento que permita entender los lazos con las ideas de ejercicio y reconocimiento de derechos. Las capacidades racionales nos identifican como humanos capaces de expresar nuestra justificación de las acciones —entre ellas, las morales_- pero ello no es suficiente cuando nos preguntamos si esa condición es única para hablar de respeto a la persona. Así, cuando se ve al otro en tanto persona, ¿qué es lo que se está viendo? Responder a esta pregunta nos ayudará a responder luego la siguiente: cuando las empresas aplican sus políticas de RSE, iestán creando escenarios que garantizan el ejercicio adecuado de derechos?

Con respecto a la segunda pregunta, nos adelantamos respondiendo afirmativamente. Nuestras razones se concentran en el siguiente argumento: la igualdad es la condición humana de vernos y tratarnos como iguales, reconociendo en el otro lo humano que compartimos y que nos diferencia.

Siguiendo lo expuesto a partir del trabajo de Habermas, una comunidad de pares es una comunidad de humanos. $O$ sea, es una comunidad humana de seres humanos con las mismas condiciones de participación en el diálogo en tanto seres racionales. Pero Habermas no habla de una condición excluyente, sino que argumenta en tanto posibilidad para la acción: todos los seres humanos son capaces, como consecuencia de su propia condición de humanos, de actuar y de justificar sus acciones racionalmente. Así, todos somos capaces porque poseemos la potencialidad de llevar a cabo acciones racionales.

Adicionalmente, esta comunidad se caracteriza por el hecho de estar conformada por individuos que comparten algo denominado humanidad en tanto condición de vida que acompaña a la condición de

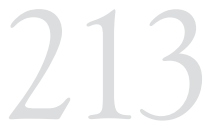

EL DIÁLOGO EN LA IMPLEMENTACIÓN

DE NORMAS DE

RSE COMO PRO-

MOTOR DEL EJER-

CICIO ADECUADO

DE DERECHOS: UN

ENFOQUE A PARTIR

DE LA ÉTICA DEL DISCURSO DE JÜRGEN HABERMAS 
seres racionales. Es decir, somos seres humanos y a la vez somos capaces de usar la razón. Acá se nos plantea una pregunta: iqué nos hace humanos? Para efectos del presente ensayo, no buscaremos una respuesta, sino consideraremos que el debate no está terminado. Pero no por ello descartamos lo siguiente: compartimos lo que uno posee y que a la vez es capaz de reconocer en el otro. Eso que yo puedo apreciar en el otro en tanto que yo lo posee es mi propia humanidad. Me reconozco humano entre humanos, y soy capaz de ver esa misma condición en otros humanos (dignidad) ${ }^{49}$.

Siguiendo a los autores de la diferencia — entre ellos Charles Taylor-, el día de hoy no se puede negar que lo que nos hace humanos no solo es aquello que todos compartimos, sino, adicionalmente, lo que nos hace únicos. Nuestra individualidad se construye mediante procesos sociales, culturales, psicológicos, geográficos, etcétera, que van influyendo en nuestro ser y que perfilan - siguiendo a E. Morin — nuestra unidimensionalidad: somos únicos y a la vez humanos. Es decir, si bien todos compartimos la humanidad, no somos idénticos, sino particulares (individualidad en tanto fundamento de la libertad).

Esta introducción a una propuesta sobre lo que reconocemos nosotros como igualdad nos coloca dentro de un discurso nuevo sobre el trato entre iguales. ¿Cómo nos tratarnos entre humanos? Según las escuelas liberales, los individuos ejercen su autonomía (libertad) a partir del debido reconocimiento de esa igualdad, esa condición de humanos diferentes: seres capaces de discernir, pero dentro de ciertos parámetros para la convivencia. Somos iguales y libres, pero rodeados de límites a nuestra actuación. En otras palabras, es en el trato cotidiano donde se aprecia nuestra capacidad para reconocer esa humanidad y respetar esa diferencia.

Luego, es en la construcción de una sociedad moderna que estos parámetros empiezan a delimitarse. Permiten el reconocimiento de posibilidades para la acción (derechos) y responsabilidades por lo que hacemos (deberes). Planteamos un siguiente argumento necesario luego del primero: sólo a quienes reconozco como mis iguales, les reconozco los mismos derechos y deberes que yo tengo.

Todos los seres humanos somos iguales en el sentido ya presentado. En tanto iguales —en tanto humanos y particulares-, poseemos las mismas posibilidades de acción. Estas posibilidades han sido recogidas y reconocidas en la esfera pública: derechos y deberes. Todos, en tanto iguales, tenemos los mismos derechos y los mismos deberes. Pero a su vez nuestras particularidades nos reconocen ciertos derechos especiales que apuntan a cambiar la vulnerabilidad hacia una situación de trato en condiciones de equidad. Por eso, si todos somos iguales, ergo, todos 
tenemos los mismos derechos y deberes. Y como somos capaces de darnos cuenta de que somos humanos, y de que compartimos la humanidad (dignidad), somos capaces de afirmar que los derechos que poseemos también pertenecen a otros seres humanos. Si exijo se respeten mis derechos en el trato cotidiano, puedo entender que otro puede, a su vez, exigir lo mismo. La exigencia por el respeto y el cumplimiento de derechos se lleva luego a un plano dialógico para el reconocimiento. Ello permite encontrar el interés generalizable en el ámbito público o social, que a su vez puede ser simbolizado en la elaboración de los marcos de RSE.

$\mathrm{Si}$, como ya señalamos, el marco normativo de la RSE es resultado de un diálogo entre iguales, se presumirá entonces que tanto en la elaboración de las pautas o límites para la acción, así como en la implementación o trato cotidiano, la condición de iguales se mantiene y se debe reforzar. De este modo, si las líneas de acción de la RSE se fundamentan en un trato en igualdad de condiciones entre las empresas - por ejemplo, extractivas-y sus grupos de interés - por ejemplo, comunidades locales-, se genera un escenario propicio para el ejercicio adecuado de derechos y deberes. Así y para concluir, en el trato entre los iguales que participan en el diálogo que busca la elaboración de normas de conducta plasmadas en principios de RSE, se consolida un escenario capaz de garantizar el ejercicio de los derechos y deberes de tales iguales que participaron. 